\title{
Retraction Note to: Sorghum polyphenols: plant stress, human health benefits, and industrial applications
}

\author{
Pummy Kumari $^{1}$ [ $\cdot$ Vinod Kumar $^{2} \cdot$ Rakesh Kumar $^{3} \cdot$ Surender Kumar Pahuja ${ }^{1}$
}

Published online: 12 October 2021

○) Springer-Verlag GmbH Germany, part of Springer Nature 2021

\section{Retraction to: Planta (2021) 254:47 https:// doi.org/10.1007/s00425-021- 03697-y}

The Editor-in-Chief has retracted this article due to substantial text overlap with previous published articles [1] and [2] by other authors.

All authors agree to this retraction.

\section{References}

1. Xiong Y, Zhang P, Warner RD, Fang Z (2019) Sorghum grain: From genotype, nutrition, and phenolic profile to its health benefits and food applications. Compr Rev Food Sci Food Saf 18(6):2025-2046

2. de Morais Cardoso L, Pinheiro SS, Martino HSD, PinheiroSant'Ana, HM (2017) Sorghum (Sorghum bicolor L): Nutrients, bioactive compounds, and potential impact on human health. Crit Rev Food Sci Nutr 57(2):372-390

Publisher's Note Springer Nature remains neutral with regard to jurisdictional claims in published maps and institutional affiliations.

The original article can be found online at https://doi.org/10.1007/ s00425-021-03697-y.

Pummy Kumari

pummy.gpb@hau.ac.in

1 Department of Plant Breeding and Genetics, COA, CCS Haryana Agricultural University, Hisar 125004, Haryana, India

2 Department of Biochemistry, COBS\&H, CCS Haryana Agricultural University, Hisar 125004, Haryana, India

3 Department of Microbiology, COBS\&H, CCS Haryana Agricultural University, Hisar 125004, Haryana, India 